\title{
Ethel García Buchard, Prácticas electorales y cultura política en Honduras durante el siglo XIX (1812-1894)
}

\section{Manuel Chust Calero'}

Estamos ante un libro de madurez. De madurez intelectual. No lo decimos solo por la autora que, notablemente también, sino por la mención que desde hace unas décadas merecen bastantes historiadores e historiadoras centroamericanos, en especial, sobre estos temas nodales del siglo XIX. Y ese bagaje historiográfico sobre la temática de los procesos electorales y la construcción de la ciudadanía en el ochocientos, se nota y mucho en la presente obra, la cual no hace más que refrendar, con mérito y excelencia, esta consideración.

El libro que tenemos la suerte de reseñar es representante de esta renovación historiográfica a la que aludimos. Y lo decimos desde el conocimiento de gran parte de la historiografía que ha contribuido a cambiar la perspectiva no solo de análisis sino también de interpretación del ochocientos centroamericano. Qué duda cabe de que un cúmulo de factores, que en esta ocasión omitimos porque no corresponde a este espacio, ha contribuido a ello.

Esta aludida madurez, intelectual e historiográfica, del libro de la profesora García Buchard contribuye -y quizá esta es una de sus grandes aportaciones- a deshacer tópicos e interpretaciones ahistóricas. Y esto, al menos para nosotros, tiene mucho mérito dado el contexto historiográfico imperante, desde los años sesenta del siglo XX.

Nos explicamos. A menudo la visión del siglo XIX latinoamericano, tanto en general como en el caso centroamericano, estaba notablemente influida por diversas interpretaciones que actuaban, si bien desde diversas y a veces antagónicas historiografías, como pesadas losas monolíticas que dictaban una sentencia desde la historia del siglo XIX. En primer lugar, la historia tradicional u oficial siguió las pautas canónicas de sacralizar la historia de la fundación de la nación al establecer binomios disyuntivos entre buenos patriotas y malos realistas. La historia se convirtió así en un relato, en una crónica de acontecimientos, especialmente bélicos, de héroes y villanos, y su interpretación se redujo a simplificar sus conclusiones y trasladarlas, hábilmente, a la población. Su éxito estuvo asegurado por décadas. Así, esta interpretación

1 Español. Doctor en Geografía e Historia. Catedrático de Historia Contemporánea de América Latina, del Departamento de Historia, Geografía y Arte de la Universidad Jaume I de Castellón, España. Correo electrónico: chust@his.uji.es 
de la historia de la Nación, la que se transformó en historia nacional, se canonizó y estatalizó. Su propósito era homogeneizar con la bandera nacional la desigualdad económica y social, la diversidad étnica y racial, y centralizar las identidades regionales. Y triunfó aplastantemente.

En segundo lugar, sabemos que también hubo una notable reacción a esta historia patria, nacional y nacionalista, desde la década de 1960, pero la mayor parte del abordaje se hizo desde la perspectiva de las ciencias sociales. La reacción a esta historia política tradicional fue hegemonizada, en general, por profesionales de las ciencias sociales, muchos de ellos atraídos y formados en universidades occidentales o latinoamericanas que monopolizaron desde varias perspectivas la interpretación del ochocientos, haciendo recaer en él tres considerandos: el primero fue que primaron las continuidades frente a los cambios y rupturas, por lo que no se vislumbraba en este siglo ningún momento revolucionario. El segundo, especialmente influidos por la Teoría de la Dependencia, fue que el siglo XIX heredó de la Colonia una economía dependiente capitalista, germen del subdesarrollo del siglo XX latinoamericano. El tercero, que no hubo ninguna revolución social decimonónica, por lo que las independencias nunca pudieron tener este rango revolucionario, dado que solo supusieron, en el mejor de los casos, una revolución eminentemente política.

Esta interpretación dejó dos responsables: la primera fue que toda revolución, su verificación o su fracaso, se pasó por el tamiz del potente haz de las revoluciones del siglo XX, especialmente, la mexicana, la rusa, la china $\mathrm{y}$, sobre manera, la cubana. La segunda fraguó una conjunción que se rebeló como un anatema: el liberalismo no pudo ser, en ninguna etapa histórica, revolucionario. Ni qué decir tiene que estos análisis sobre la historia del ochocientos, en especial de la primera mitad, adolecieron no solo de un análisis histórico sino de una perspectiva eminentemente presentista y, por lo tanto, ahistórica.

Es por ello, entre otras circunstancias, que damos la bienvenida al libro de la profesora García Buchard. Por varias razones, que son a la vez la fortaleza de este estudio. La primera es que está basado en un exhaustivo análisis de fuentes primarias, lo que deviene, por lo tanto, en la presentación de una tesis fundamentada en estas y no en la mera especulación. Dado los tiempos, un regreso a la interpretación de fuentes es saludable. La segunda porque traslada un análisis del siglo XIX hondureño, si bien desde la política y prácticas electorales, dinámico, de avances y retrocesos, de conquistas y derrotas y, por tanto, histórico. Así se huye de la visión plana y tópica de un ochocientos monolítico. La tercera razón nos parece aún más importante, y por ello nuestra calificación de este estudio como madurez intelectual, dado que se enfrenta valientemente a uno de los tópicos más frecuentes que calificaban - o descalificaban- al siglo XIX como la centuria del desorden, del caos, de la inestabilidad de su sistema político... Por el contrario, de forma brillante, 
García Buchard demuestra la potencialidad que, desde la Constitución de 1812, parte del sistema liberal brindó al poder local a los ayuntamientos, a los municipios, a la movilización de sus pobladores, a su politización y a su participación e incorporación por medio de la política de derechos civiles. Estos aspectos generarían una quiebra del monopolio centralizado de la representación y de la soberanía, provocando una ruptura con la estructura del régimen colonial. Así, el calificado de desorden liberal decimonónico tendría su raíz en la comparación de este frente al orden colonial. Interpretación colonialista, no exenta de moderantismo historiográfico. Tesis, la de García Buchard, que se nos revela como una de las grandes aportaciones de este estudio.

Qué duda cabe de que este trabajo de madurez es deudor de la formación incansable, y nos consta que la profesora García Buchard ha seguido a lo largo de su trayectoria. Y qué duda cabe que esa otra mirada quizá también tenga que ver, al menos un poco, con su paso posdoctoral por una de las universidades en donde la visión de la historia de América constituye un referente de renovación historiográfica desde hace algunas décadas: la Universidad Pablo de Olavide en Sevilla.

El libro está estructurado en cinco capítulos. En ellos se hace un comedido repaso, tanto factual como interpretativo, de la construcción de la ciudadanía y de la cultura política en la sociedad hondureña, desde la independencia hasta fines del siglo XIX. En el primer capítulo, que está pensado a modo de síntesis, la autora hace un análisis del concepto de ciudadano y su evolución durante todo el siglo XIX, destacando la duplicidad de categorías, tanto la de elector como la de elegible, no siempre coincidentes. Los siguientes tres capítulos son diacrónicos, dado que García Buchard establece, a modo de periodización, tres etapas de los procesos electorales en Honduras, coincidentes con estos tres capítulos. La primera sería la que comenzaría con la Constitución de 1812 y su aplicación en la Capitanía de Guatemala, hasta el año 1838. Por supuesto que esta cronología, aunque no novedosa para Centroamérica, se enmarca dentro de la corriente historiográfica renovadora desde los años noventa del siglo XX, en la cual se destaca el papel pionero y original del constitucionalismo doceañista y su legado en los distintos territorios americanos. La segunda etapa, que conforma el tercer capítulo, aborda la significación del sufragio en la vida política del periodo republicano que se circunscribe entre 1838 y 1865. Por último, la autora dedica la tercera etapa, y cuarto capítulo del libro, desde esta fecha hasta 1877.

Mención especial hay que dedicarle al último capítulo, el quinto, quizá uno de los más atractivos para la persona lectora, en donde la historiadora hondureña-costarricense hace un interesante y sugerente estudio sobre los medios de comunicación y sus formas de conexión con los procesos electorales, en especial los diarios, los manifiestos y las proclamas. 
Justamente en estos momentos en los que escribimos la reseña de este importante libro, la actualidad política de Honduras asalta al relato histórico. Cómo no recordar algunas de las circunstancias de el proceso electoral de noviembre de 2017, sin hacer una retrospectiva de lo leído por este historiador en las páginas del libro de García Buchard. La lucha por la democracia prosigue, pero queda explicitada en su máximo rigor académico en muchas de las meritorias páginas de este libro, consecuentemente premiado.

\section{Referencia}

García Buchard, Ethel. (2017). Prácticas electorales y cultura política en Honduras durante el siglo XIX (1812-189). Tegucigalpa: Editorial Guaymuras. 